\title{
Subtractive versus Multiplicative Habits in Environmental Economics
}

\section{Fatma SAFI", Lobna Ben Hassen ${ }^{* *}$}

\begin{abstract}
The present paper presents overlapping generations set-up with internal habits in consumption and the presence of environmental quality in the utility function. The modeling of habits implies that the consumer preferences are influenced not only by a household's own current consumption, but also by their personal past consumption. Our main objective is to study and compare the impacts of first subtractive second multiplicative internal habits on the environmental quality and the capital accumulation through a comparative static behavior at the stable steady state equilibrium. By changing the way the habit is specified, we have shown that introducing habit can lead to different findings regarding the capital and the environment.
\end{abstract}

Keywords: Subtractive and multiplicative habits, overlapping generations, environmental quality, consumption.

JEL: D11, D91, Q20

\section{Introduction}

Economic literature has investigated the of individual preferences depending on time, risk or social interactions. Among them the internal habits in consumption have attracted specific interest. In fact, great importance is attached to the standard of living by individuals who show a tendency to stick to old habits. They will possibly stop caring about environmental quality in order to pursue their higher lifestyle. Theoretically speaking, the idea that private utility depends on relative, rather than on absolute consumption levels, is attracting considerable attention in the economic growth literature. When an agent's utility is influenced by their own past consumption, the agent is said to form an "internal habits stock".

The internal habit stock indicates that the current level of utility is influenced by the accumulated stock of past private consumption. As in this condition the future utility depends on the choice of current consumption, a rational consumer takes this information into account in choosing his optimal consumption program. Chetty and Szeidl (2016) explore the consequences of agent-level adjustment costs for the dynamics of aggregate consumption. They demonstrated that an economy in which individuals have "consumption commitments" is almost equivalent to a habit formation model in which the habit stock is a weighted average of past consumption if idiosyncratic

\footnotetext{
Department of Economics, Faculty of Economics and Management, University of Sfax, Street of Airport, km 4.5, LP 1088, Sfax 3018, Tunisia.

*Faculty of Economics and Management of Sfax, Tunisia.
} 


\section{Articles}

risk is large relative to aggregate risk. There is abundant literature displaying habit in the macroeconomic data but no evidence in the microeconomic data (Havranek et al. (2018) and Carroll et al. (2020).

Habits formation is a characteristic feature of consumption decisions. It plays a key role in the analysis of the relationship between consumption decisions and their associated externalities as regards environmental quality. A lot of evidence shows that our daily lives demand more resources and intensify pressure on the environment, due to our habitual behaviour (e.g., increase of the number ofshowers per day, air-conditioned rooms...). Arrow (1973) assumes that any consumption lifestyle forms habits. This vision is also highlighted by psychological results. For instance, Klöckner et al. (2003) and Klöckner and Matthies (2004), who are psychologists, indicate that strong car choice habits prevent the procedure of normative decision-making. With weighty habits, personal standards to care for the environment have barely any impact on behavior (Klöckner et al. 2003).

To identify the economic interaction between habit consumption and the environment, Löfgren (2003) develops a model in which individuals form habit formation in environmental quality, and shows the optimal taxation that is influenced by habits. Valente (2006) determines to which degree, habits change steady state consumption and capital in the presence of pollution externalities. In the OLG model, Wendner (2000a) takes an interest in environmentally harmful production. Wendner (2000b) focuses on environmentally harmful consumption, but his major concern is about the design of optimal tax schemes; how habit influences environmental quality via consumption is not considered. Ono (2002) implements maintenance efforts of consumers into an overlapping generations model. He investigates the theoretical relationship between habit and the environment through environmentally harmful consumption influenced by habitual behavior. Schumacher and Zou (2008) indicate that habit in pollution has not only important effects on the level of pollution and capital, but also on the evolution of utility over time and can be another cause of intergenerational inequity. Chen and $\mathrm{Li}$ (2011) examine habits in environmental quality and conclude that there is a possible chaotic behavior for their one dimensional system. Bezin (2012) presents an OLG model such that the pollution and the environmental care are endogenous. Aronsson and JohanssonStenman (2014) explore, in a set-up where individuals care about conspicuous consumption, the optimal provision of public goods. Furthermore, the literature on habit persistence identifies preferences either using subtractive habits (SH) or multiplicative habits $(\mathrm{MH})$, as stated by the terminology introduced by Carroll (2000).Practically, even though habits highlighted numerous economic phenomena, not much attention has been paid to the economic outcomes of these two alternative specifications. In the risk premium context, Abel (1990) and Constantinides (1990) achieve similar results with MS and MH. Wendner (2003) states that these specifications may point to opposite conclusions as regards consumer savings behavior. He states that when a rise in habits is observed, young consumers may raise savings in the case of $\mathrm{SH}$, while they may reduce savings in the case of $\mathrm{MH}$. In addition, Carroll (2000) shows that under plausible parameter values, SH may lead to a not welldefined utility in stochastic environments as opposed to $\mathrm{MH}$. Bossi and Porqueras (2009) shed light on this issue and examine the consequences of modeling different forms of habit persistence in a pure exchange, twoperiod lived overlapping generations model and find that specifying preferences with $\mathrm{MH}$ 


\section{Articles}

or SH produces theoretical outcomes that are not necessarily equivalent.

Our main contribution is to study and compare the economic consequences of these two formulations as Bossi and Porqueras (2009) did, but in an environmental context. In order to do that, we examine in an overlapping generations framework along the lines of John and Pecchenino (1994) where agents form internal habits in consumption and are subject to an environmental constraint in which consumption by both young and old generations exerts a non-positive impact on environmental quality which can be at least partially compensated by maintenance expenditure. We focus particularly on the determination of the impacts of two specifications of internal habits: $\mathrm{SH}$ and $\mathrm{MH}$ on environmental quality and capital accumulation and the comparison between these two impacts by studying the comparative static analysis at the stable steady state equilibrium. This paper shows that two of the most common formulations of internal habits may easily come to opposite conclusions.

This paper is organized as follows: In Section 2 we introduce the model first with subtractive habit second in the case of multiplicative habits. In both subsections, we focus on the competitive equilibrium, the stability properties of the long-run equilibrium, the steady state and its comparative static behavior. Section 3 presents the conclusions.

\section{The model}

Consider an infinite-horizon economy comprised of two-period-lived overlapping generations. A new generation is born in each period $t=1,2, \ldots$ The size of a newly born generation is normalized to one. Each generation lives for two periods, youth and old age, and obtains utility from consumption and environmental quality in both periods. Let $c_{t}^{1}$ denote consumption of generation $t$
Subtractive versus Multiplicative Habits in Environmental Economics

in the first period (youth), $c_{t+1}^{2}$ consumption of generation $t$ in the second period (old age). The young generation receives a wage rate $w_{t}$ per unit of labor. This is allocated to consumption $c_{t}^{1}$, savings $s_{t}$ and maintenance investment $m_{t}$.Both savings and interest on savings $R$ are fully consumed by the old generation.

The individuals' constraints over the two periods can therefore be summarized as follows:

$$
\begin{aligned}
& w_{t}=c_{t}^{1}+s_{t}+m_{t} \\
& c_{t+1}^{2}=R_{t+1} s_{t}
\end{aligned}
$$

These constraints are summarized as the life-cycle budget constraint:

$c_{t}^{1}+c_{t+1}^{2} / R_{t+1}+m_{t}=w_{t}$

Following John and Pecchenino (1994), we assume that the environmental quality can be worsened by economic consumption and improved by maintenance investment, according to the following law of motion

$E_{t+1}=E_{t}-\beta\left(c_{t}^{1}+c_{t}^{2}\right)+\delta m_{t}$

where $E_{t}$ is the index of environmental quality in period $t, \beta>0$ is a parameter of consumption externalities, $c_{t}^{1}+c_{t}^{2}$ is the aggregate consumption in period $t, \delta>0$ is a parameter that represents the technology for maintenance investment, and $m_{t}$ is the aggregate maintenance investment made for the environment in period $t$. The maintenance activity in period $t$ is conducted by generation $t$ since this generation can enjoy the improved environmental quality in its old age.

The individual's utility $U$ is derived from consumption and environmental quality in the first and second periods. We suppose $U($.$) is strictly increasing, strictly concave,$ homogeneous, and twice continuously differentiable where $U^{\prime}{ }_{c_{t}^{1}}>0 ; U_{\hat{c}_{t+1}^{2}}^{\prime}>0$; $U_{E_{t}}^{\prime}>0 ; \quad U_{E_{t+1}}^{\prime}>0$ and $U^{t_{t+1}}{ }_{c_{t}^{1}}<0$; $U^{\prime \prime}{ }_{\hat{c}_{t+1}^{2}}<0 ; U^{\prime \prime} E_{t}<0 ; U^{\prime \prime} E_{t+1}<0$. However, due to the presence of habit formation, 


\section{Articles}

utility depends not only on the level of its consumption but also on a reference level of past consumption. Like Ono (2002), habit is supposed to appear in such a way that higher first-period consumption decreases the utility from a given level of second-period consumption. The concept of habit has long been acknowledged as being the important characteristic of human behavior. The idea that the overall level of satisfaction derived from a given level of consumption depends, not only on the (current) consumption level itself, but also on how it compares with some benchmark level, is not new.

Generally, environmental externalities can result from either production or consumption. In our model, the externality arises from consumption ${ }^{1}$. When the environment is introduced into the individuals' utilities, variations in environmental quality change the marginal rate of substitution between consumption and environment, yielding individuals to modify their allocation of resources between consumption and environmental enhancement. On the other hand, when externalities work through the technology, variations in environmental quality influence the total resources available. ${ }^{2}$

Formally, preferences of each individual are defined by the lifetime utility $U$ :

$$
\begin{gathered}
U_{t}=U\left(c_{t}^{1}\right)+U\left(\hat{c}_{t+1}^{2}\right)+U\left(E_{t}\right)+ \\
U\left(E_{t+1}\right)
\end{gathered}
$$

where $\hat{c}_{t+1}^{2}$ is the effective consumption in old age. For the sake of simplicity, we assume that the individual's utility function is a log-linear function. Thus,
$U\left(c_{t}^{1}\right)=\ln c_{t}^{1}, U\left(\hat{c}_{t+1}^{2}\right)=\ln \hat{c}_{t+1}^{2}, \quad$ and $U\left(E_{t+1}\right)=\ln E_{t+1}$.

Let effective old-age consumption be presented by some general function

$$
\hat{c}_{t+1}^{2}=U\left(c_{t+1}^{2}, c_{t}^{1}\right)
$$

Following Lahiri and Puhakka (1998), Wendner (2002), instantaneous utility in the second period of life is derived from the difference of current consumption and a fraction of past consumption.

In what follows, when we deal with the subtractive form of habit formation, we specify $U\left(c_{t+1}^{2}, c_{t}^{1}\right)$ in such a way that

$$
U\left(c_{t+1}^{2}, c_{t}^{1}\right)=c_{t+1}^{2}-\sigma c_{t}^{1}
$$

When we discuss the model with multiplicative habit, we use as Alonso-Carrera et al. (2005), Alverz-Cuadrado et al. (2007), Bunzel (2006) and Carroll et al. (1997, 2000) did, the following specification

$$
U\left(c_{t+1}^{2}, c_{t}^{1}\right)=c_{t+1}^{2}\left(c_{t}^{1}\right)^{-\sigma}
$$

where $\sigma \geq 0$ indexes the strength of habits or the importance of past consumption in the instantaneous utility function. The weight that is attached to past consumption increases in $\sigma$. If $\sigma=0$, the past consumption has no weight at all.

The following properties, $P(1)$ and $P(2)$, define the effective old-age consumption.

$\partial U\left(c_{t+1}^{2}, c_{t}^{1}\right) / \partial c_{t+1}^{2}>0$

$P(1)$ requires that, with no change in first period consumption, a rise in second period consumption raises the effective old-age consumption utility.

$\partial U\left(c_{t+1}^{2}, c_{t}^{1}\right) / \partial c_{t}^{1}<0$

(P2) requires that, with no change in second period consumption, a rise in

\footnotetext{
${ }^{1}$ We can also consider the externality as rising from production by changing the technology for environmental enhancement.

${ }^{2}$ For example, in Ono (2003) the environment has an effect on technology. Bovenberg and Smulders (1995) develop a model such that environment has an effect on both utility and technology.
} 


\section{Articles}

first period consumption cannot raise the effective old-age consumption utility $U\left(c_{t+1}^{2}, c_{t}^{1}\right)$ and may cause it to reduce.

The following properties, $P(3)$ and $P(4)$, represent an important summary of consumer behavior when consumers form habits. If they are not fulfilled, a consumer will respond to an increase in the strength of habits - contrary to what is expected - with a reduction in its optimal rate of consumption growth. These two properties can be expressed formally as follows

$\partial U\left(c_{t+1}^{2}, c_{t}^{1}\right) / \partial \sigma<0$

Property $(\mathrm{P} 3)$ requires that a rise in the stock of habits, as measured by $\sigma$, with no change in first or second period consumption decreases effective old-age consumption utility $U\left(c_{t+1}^{2}, c_{t}^{1}\right)$. Deaton (1992) puts it, "the larger the $\sigma$, the less the pleasure from a given amount of consumption, and the larger must be purchases to generate the same benefit." $\partial M R S_{c_{t}^{1} / c_{t+1}^{2}} / \partial \sigma<0$

Property $(\mathrm{P} 4)$ requires that a rise in the strength of a given habit stock in period $t$; as measured by $\sigma$, with no change in first or second period consumption, decreases $M R S_{c_{t}^{1} / c_{t+1}^{2}}$ at a given consumption path. As $\sigma$ increases, a consumer attaches more importance to consumption growth as opposed to the consumption level in its utility function. Therefore, we expect consumers to shift consumption from the present to the future to increase the rate of consumption growth ${ }^{3}$.

In the present analysis, the economy is facing two types of intergenerational externalities. The first one is attributable to internal habits as a frame of reference originating in the consumption of the previous period. The second is attributable to the effect of present consumption decisions on the level
Subtractive versus Multiplicative Habits in Environmental Economics

of environmental quality enjoyed by upcoming generations.

The state variables of the economy are the environmental quality $E$ and capital $k$.The law of motion of capital is given by the equilibrium relation between savings and investment. As we have assumed full depreciation of capital, net savings determine the capital stock in the next period

$k_{t+1}=s_{t}$

The firms are perfectly competitive profit maximizers that produce output using the production function $F\left(K_{t}, L_{t}\right)=Y_{t} . K_{t}$ is the capital stock in period $t, L_{t}$ is the employment in period $t$. The production function can be written in the intensive form

$y_{t}=f\left(k_{t}\right)$

where $y_{t}$ and $k_{t}$ are output and capital per worker respectively and $f(k) \equiv F(k, 1)$. The following assumption characterizes the production function;

Assumption: The production function $f: R_{+} \Rightarrow R_{+}$has the following properties. It is twice continuously differentiable, increasing and strictly concave. In particular, $f^{\prime}\left(k_{t}\right)>0$; $f^{\prime \prime}\left(k_{t}\right)<0 ; k f^{\prime \prime}(k)+f^{\prime}(k)>0 \forall k>0$. Moreover, we suppose that $\lim _{k \rightarrow \infty} f^{\prime}\left(k_{t}\right)=0$, $\lim _{k \rightarrow 0} f^{\prime}\left(k_{t}\right)=\infty$ and $f(0) \stackrel{k \rightarrow \infty}{=}$.

In the following analysis, we explore the consistency of both the subtractive and the multiplicative specifications of habit formation with properties (P1) to (P4). Next we examine the analytical consequences of these two specifications and see whether the dynamic stability of the economy and the steady state equilibrium are influenced by the way consumption habits are introduced into the utility function as in Bossi and Porqueras (2009) but in an environmental framework.

${ }^{3}$ See Wendner (2003) 


\section{Articles}

We discuss in the following subsection the comparative static analysis at the stable steady state equilibrium with $\mathrm{SH}$ and we show their effects on capital and the environment.

\subsection{Subtractive habits}

Since our framework is theoretical, we built it following seminal works using an OLG model. Wendner (2000a) focuses on environmentally harmful production however he did not reflect the environmentally harmful consumption. Wendner (2000b) assumes environmentally harmful consumption and explored the design of optimal tax schemes. The impact of habit on environmental quality through consumption is examined then by Ono (2002). We revisit this topic by introducing into the Ono (2002) model the physical capital and study the effects of SH on capital and the environment. We reach more straightforward results.

Verification of properties (1) and (2) for subtractive specification:

$\partial U\left(c_{t+1}^{2}, c_{t}^{1}\right) / \partial c_{t+1}^{2}=\partial \hat{c}_{t+1}^{2} / \partial c_{t+1}^{2}=$ $=U^{\prime}\left(\hat{c}_{t+1}^{2}\right)>0$,

$\partial U\left(c_{t+1}^{2}, c_{t}^{1}\right) / \partial c_{t}^{1}=-\sigma U^{\prime}\left(\hat{c}_{t+1}^{2}\right)<0$

Thus, the subtractive formulation is consistent with properties (1) and (2).

Verification of property (3) for subtractive specification:

$\partial U\left(c_{t+1}^{2}, c_{t}^{1}\right) / \partial \sigma=-c_{t}^{1} U^{\prime}\left(\hat{c}_{t+1}^{2}\right)<0$

An increase in $\sigma$ raises the importance of habits. Thus, effective consumption declines and so does utility. Therefore, (P1) holds.

Verification of property (4) for subtractive specification:

The marginal rate of substitution equals:

$$
\begin{aligned}
& M R S_{c_{t}^{1} / c_{t+1}^{2}}=\frac{\partial U_{t} / \partial c_{t}^{1}}{\partial U_{t} / \partial c_{t+1}^{2}}= \\
& =\frac{U^{\prime}\left(c_{t}^{1}\right)-\sigma U^{\prime}\left(\hat{c}_{t+1}^{2}\right)-\beta U^{\prime}\left(E_{t+1}\right)}{U^{\prime}\left(\hat{c}_{t+1}^{2}\right)}
\end{aligned}
$$

Differentiating the marginal rate of substitution with respect to $\sigma$ yields

$$
\begin{aligned}
& \frac{\partial M R S_{c_{t}^{1} / c_{t+1}^{2}}}{\partial \sigma}=\frac{U^{\prime}\left(\hat{c}_{t+1}^{2}\right)\left[-U^{\prime}\left(\hat{c}_{t+1}^{2}\right)+\right.}{} \\
& \frac{\left.+\sigma c_{t}^{1} U^{\prime \prime}\left(\hat{c}_{t+1}^{2}\right)\right]+c_{t}^{1} U^{\prime \prime}\left(\hat{c}_{t+1}^{2}\right) \partial U_{t} / \partial c_{t}^{1}}{\left[U^{\prime}\left(\hat{c}_{t+1}^{2}\right)\right]^{2}}<0
\end{aligned}
$$

Under the usual assumptions that $U^{\prime}\left(c_{t}^{1}\right)>0$ and $U^{\prime \prime}\left(\hat{c}_{t+1}^{2}\right)<0$, the derivative is always negative and the subtractive formulation is consistent with (P4).

\subsubsection{Laissez-faire Equilibrium}

The individual chooses $\left\{c_{t}^{1}, c_{t+1}^{2}, s_{t}, m_{t}\right\}$ to maximize his utility subject to the life-cycle budget constraint (3) and to the environmental equation (4).

We use the constraints (3) and (4) to write down the objective function of the individual as $U=\ln c_{t}^{1}+\ln \left[R_{t+1}\left(w_{t}-c_{t}^{1}-m_{t}\right)-\sigma c_{t}^{1}\right]$

$$
+\ln E_{t}+\ln \left[E_{t}-\beta\left(c_{t}^{1}+c_{t}^{2}\right)+\delta m_{t}\right]
$$

By deriving (8) with respect to $m_{t}$, we get

$R_{t+1} \frac{1}{\hat{\mathrm{c}}_{\mathrm{t}+1}^{2}}=\delta \frac{1}{\mathrm{E}_{\mathrm{t}+1}}$

By deriving (8) with respect to $c_{t}^{1}$, we get

$\frac{1}{c_{t}^{1}}=\left(\beta+\delta+\frac{\delta \sigma}{R_{t+1}}\right) \frac{1}{E_{t+1}}$

The equations (9) and (10) represent the first-order conditions which characterize the outcome of generations.

Equation (9) states that generation $t$ chooses savings, equating the marginal rate of substitution between the effective consumption in old age $c_{t+1}^{2}-\sigma c_{t}^{1}$, and environmental quality in old age to the marginal rate of transformation $\frac{\delta}{R_{t+1}}$. At the utility maximum, a decrease in utility due to falling of old consumption, is equal to an increase in utility due to an increase in maintenance effort $\delta$.

Equation (10) states that generation $t$ chooses consumption when young, equating 


\section{Articles}

the marginal rate of substitution between consumption in youth and environmental quality in old age to the marginal rate of transformation $\left(\beta+\delta+\frac{\delta \sigma}{R_{t+1}}\right)$. At the utility maximum, a decrease in utility due to falling consumption during youth is equal to an increase in utility due to the sum of an increase in maintenance effort, $\delta\left(1+\frac{\sigma}{R_{t+1}}\right)$, and a decrease in a consumption externality, $\beta$. If $\sigma$ increases, so does the second term of the first order condition (10). A unit of first period consumption raises the marginal utility of second period consumption. Thus, the higher $\sigma$ is, the lower the optimal first period consumption.

Assuming perfect competition in the factor markets, the profit-maximization problem yields the following factor prices

$w_{t}=f\left(k_{t}\right)-k_{t} f^{\prime}\left(k_{t}\right)$

$R_{t}=f^{\prime}\left(k_{t}\right)$

where (11) and (12) state that the firm hires labor and capital until the marginal products equal the factor prices. As we assume a constant returns production technology and inelastic labor supply, (11) and (12) also define factor markets clearing.

A competitive equilibrium for the economy under analysis is a sequence of $\left\{c_{t}^{1}, c_{t+1}^{2}, s_{t}, m_{t}, w_{t}, r_{t}, k_{t}, E_{t}\right\}_{t=0}^{\infty}$ such that, given the initial conditions of the state parameters $k_{0}$ and $E_{0}$ : i) firms maximize profits; ii) consumers maximize their utility function; iii) markets clear.

The first-order conditions of the utility maximization are (3)-(6)-(9) and (10), and the first-order conditions of profit maximization are (11) and(12). A market clearing condition for capital is (5).

Under the hypothesis that $m>0$, the first order conditions of the individual's maximization problem (9) and (10)can be rewritten as follows
Subtractive versus Multiplicative Habits in Environmental Economics

$E_{t+1}=\left[\beta+\delta+\frac{\delta \sigma}{f^{\prime}\left(k_{t+1}\right)}\right] c_{t}^{1}$

$\delta\left(c_{t+1}^{2}-\sigma c_{t}^{1}\right)=R_{t+1} E_{t+1}$

Equation (14) can be solved for $c_{t+1}^{2}$,

$c_{t+1}^{2}=\frac{R_{t+1} E_{t+1}}{\delta}+\sigma c_{t}^{1}$

Substituting equation (2) and (5) into (14), $\delta\left(R_{t+1} k_{t+1}-\sigma c_{t}^{1}\right)=R_{t+1} E_{t+1}$

Substituting equation (13) into (16) gives a relation between $k_{t+1}$ and $E_{t+1}$

$\delta k_{t+1}=\left[\frac{\delta \sigma}{(\beta+\delta) f^{\prime}\left(k_{t+1}\right)+\delta \sigma}+1\right] E_{t+1}$

By plugging equations (11)-(12)-(13) and (5) into (3), it gives

$m_{t}=f\left(k_{t}\right)-k_{t} f^{\prime}\left(k_{t}\right)-\frac{E_{t+1}}{\left[\beta+\delta+\frac{\delta \sigma}{f \prime(k)}\right]}-k_{t+1}$

Plugging equations (12) and (5) into (2) gives

$c_{t+1}^{2}=k_{t+1} f^{\prime}\left(k_{t+1}\right)$

For the sake of simplicity, we standardize the population of generation $t$ as one. Therefore, by plugging equations(19) and (17) lagged once into (6) yields

$E_{t+1}=E_{t}-\beta\left(\frac{E_{t+1}}{\left[\beta+\delta+\frac{\delta \sigma}{f^{\prime}\left(k_{t}\right)}\right]}+k_{t} f^{\prime}\left(k_{t}\right)\right.$
$\left.+\delta\left[f\left(k_{t}\right)-k_{t} f^{\prime}\left(k_{t}\right)-\frac{E_{t+1}}{\left[\beta+\delta+\frac{\delta \sigma}{f^{\prime}\left(k_{t}\right)}\right]}-k_{t+1}\right]\right)$

Rearranging (17) gives

$E_{t+1}=\frac{\delta k_{t+1}\left[(\beta+\delta) f^{\prime}\left(k_{t+1}\right)+\delta \sigma\right]}{(\beta+\delta) f^{\prime}\left(k_{t+1}\right)+2 \delta \sigma}$

Equations (20) and (21) represent the law of motion for the environment.

\subsubsection{The steady state}

Since all parameters are constant in the steady state, time subscripts are eliminated. Let $\bar{k}$ and $\bar{E}$ indicate steady state values. The law of motion for the environment(20) and (21), in steady state, can be rewritten as 


\section{Articles}

$$
\begin{gathered}
\frac{(\beta+\delta) f^{\prime(\bar{k})}}{\left.\bar{E}+\delta \bar{k} f^{\prime(k)}+\delta \sigma\right]} \bar{E} f^{\prime(\bar{k})} \\
-\delta\left[f(\bar{k})-\bar{k} f^{\prime}(\bar{k})-\bar{k}\right]=0 \\
\bar{E}-\frac{\delta \bar{k}\left[(\beta+\delta) f^{\prime}(\bar{k})+\delta \sigma\right]}{(\beta+\delta) f^{\prime}(\bar{k})+2 \delta \sigma}=0
\end{gathered}
$$

The following analysis describes the comparative static behavior of the steady state of this model.

The differentiation of (22) and (23) taking $\beta$ and $\delta$ as given yields

$$
\left[\begin{array}{ll}
\mu_{1} & \mu_{2} \\
\mu_{3} & \mu_{4}
\end{array}\right]\left[\begin{array}{l}
\partial \bar{E} \\
\partial \bar{k}
\end{array}\right]=\left[\begin{array}{l}
\mu_{5} \\
\mu_{6}
\end{array}\right] \partial \sigma
$$

The determinant of the left-hand-side matrix is

$$
\begin{aligned}
& |D|=\left|\begin{array}{ll}
\mu_{1} & \mu_{2} \\
\mu_{3} & \mu_{4}
\end{array}\right| \\
& \mu_{1}=\frac{\text { where; }(\beta+\delta) f^{\prime}(\bar{k})}{\left[(\beta+\delta) f^{\prime}(\bar{k})+\delta \sigma\right]}>0 \\
& \mu_{2}=\frac{(\beta+\delta) \sigma \delta f^{\prime \prime}(\bar{k}) \bar{E}}{\left[(\beta+\delta) f^{\prime}(\bar{k})+\delta \sigma\right]^{2}}+ \\
& \beta f^{\prime}(\bar{k})+(\beta+\delta) \bar{k} f^{\prime \prime}(\bar{k})+\delta \\
& \mu_{3}=(\beta+\delta) f^{\prime}(\bar{k})+2 \delta \sigma>0 \\
& \mu_{4}=(\beta+\delta)\left\{f^{\prime \prime}(\bar{k}) \bar{E}-\right. \\
& \left.\delta\left[f^{\prime}(\bar{k})+\bar{k} f^{\prime \prime}(\bar{k})+\delta \sigma\right]\right\}<0 \\
& \mu_{5}=\frac{(\beta+\delta) \delta f^{\prime}(k) \bar{E}}{\left[(\beta+\delta) f^{\prime}(\bar{k})+\delta \sigma\right]^{2}}>0 \\
& \mu_{6}=\delta[\delta \bar{k}-2 \bar{E}]
\end{aligned}
$$

Rearranging equation (23) and substituting it into $\mu_{6}$ gives

$$
\mu_{6}=-\delta^{2} \bar{k}(\beta+\delta) f^{\prime}(\bar{k})<0
$$

The determinant of the left-hand-side matrix $|D|=\mu_{1} \mu_{4}-\mu_{2} \mu_{3}$ is negative.

\subsubsection{The stability properties of the long- run equilibrium}

The stability of the fixed point of the long-run equilibrium can be determined by examining the eigenvalues of the Jacobian matrix $J$. We first set up the Jacobian matrix of partial derivatives.
$J_{(E, k)}=\left[\begin{array}{ll}\frac{\partial E_{t+1}}{\partial E_{t}} & \frac{\partial E_{t+1}}{\partial k_{t}} \\ \frac{\partial k_{t+1}}{\partial E_{t}} & \frac{\partial k_{t+1}}{\partial k_{t}}\end{array}\right] \quad J=\left[\begin{array}{ll}\mu_{1} & \mu_{2} \\ \mu_{3} & \mu_{4}\end{array}\right]$

Now we evaluate the Jacobian matrix $J$ at the steady state.

$$
J_{\left(\bar{E}_{1}, \bar{k}_{1}\right)}=A=\left[\begin{array}{ll}
\mu_{1} & \mu_{2} \\
\mu_{3} & \mu_{4}
\end{array}\right]
$$

We obtain the eigenvalues by solving the characteristic polynomial $P(\lambda)=\operatorname{det}(A-\lambda I)=0$.

$P(\lambda)=\left|\begin{array}{cc}\mu_{1}-\lambda & \mu_{2} \\ \mu_{3} & \mu_{4}-\lambda\end{array}\right|=0$
$\lambda_{1}=\frac{\mu_{1}+\mu_{4}+\sqrt{\left(\mu_{1}-\mu_{4}\right)^{2}+4 \mu_{2} \mu_{3}}}{\mu_{2}+\mu_{4}-\sqrt{\left(\mu_{1}^{2}-\mu_{4}\right)^{2}+4 \mu_{2} \mu_{3}}}$
$\lambda_{2}=\frac{\mu_{1}}{2}$

The eigenvalues are then $\lambda_{1}$ and $\lambda_{2}$. The stability properties of the long-run equilibrium can be studied by proving that the partial derivatives have moduli strictly less than one, that is $\left|\lambda_{i}\right| \leq 1$ for all $i$. Hence we can conclude that the system converges to a longrun equilibrium which is asymptotically stable if $\mu_{1}<-\mu_{4}$.

Proof. See Appendix A.

\subsubsection{The effects of subtractive habits on capital and environment}

We study the effects of internal habit in subtractive form on the steady state equilibrium level of capital accumulation and environmental quality.

The effects of $\mathrm{SH}$ on capital accumulation

$$
\frac{\partial \bar{k}}{\partial \sigma}=\frac{1}{|D|}\left\{\mu_{1} \mu_{6}-\mu_{3} \mu_{5}\right\}>0
$$

The effects of $\mathrm{SH}$ on the environment

$$
\frac{\partial \bar{E}}{\partial \sigma}=\frac{1}{|D|}\left\{\mu_{4} \mu_{5}-\mu_{2} \mu_{6}\right\}>0
$$

Proof. See Appendix B.

Proposition: with subtractive specification, economies with higher habit stock have higher capital accumulation and higher environmental quality in steady state. 


\section{Articles}

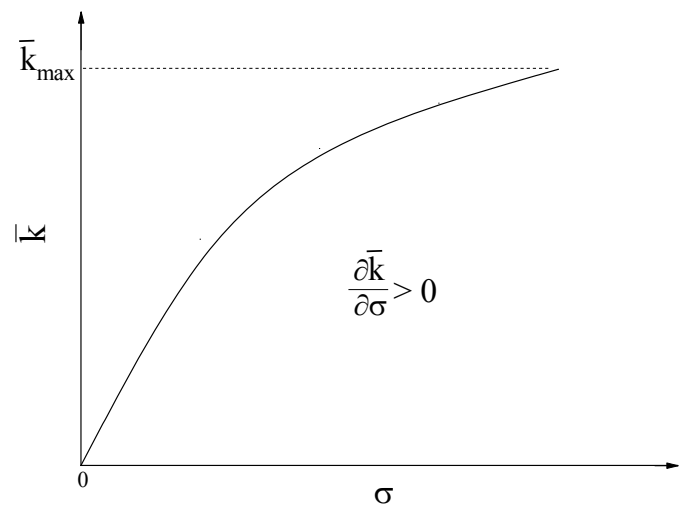

Fig. 1: Effect of SH on environmental quality

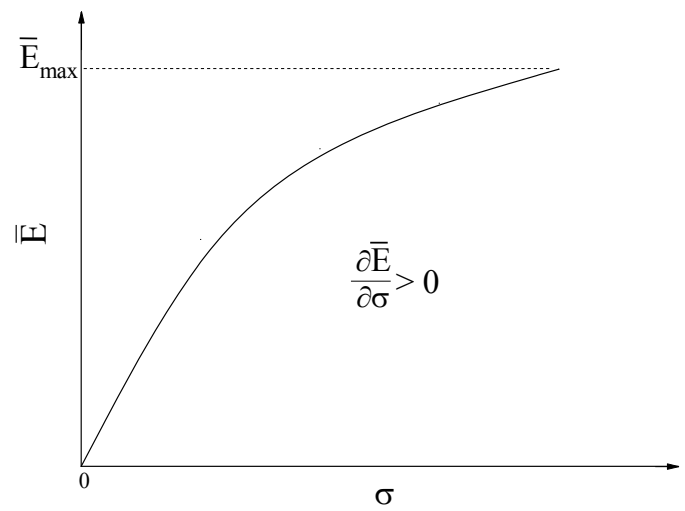

Fig. 2: Effect of SH on capital accumulation

To some extent, we obtain different results from those obtained in the literature. For instance, Wendner (2000a) argued that $\mathrm{SH}$ of consumption is usually harmful to the environment. In fact, the difference with his results comes from the following two assumptions. First, he supposes that production worsens the environment, whereas our framework supposes that it is decreased by consumption. Second, he spotlights the behavior of an uninvolved household in environmental issues, whereas our framework focuses on a representative household which is concerned about the quality of the environment when they are old by investing in maintenance when young. Ono (2002) introduces a model using storage technology and a constant intertemporal elasticity of substitution function
Subtractive versus Multiplicative Habits in Environmental Economics

(CIES) and showed that SH have an ambiguous effect on the environment. He stated that habit in consumption has both negative and positive effects on environmental quality. Whether the positive effect dominates the negative one depends on the degrees of habit formation and environmental externalities. We revisit this topic by introducing into the Ono (2002) model the physical capital and by using a log linear utility function. Our main finding is straightforward: economies with greater $\mathrm{SH}$ stock in consumption accumulate more capital and benefice from a better environmental quality.

The economic intuition behind this result is: habits affect environmental quality and capital accumulation through two channels via consumption. On one hand, higher habits yield to a decrease in consumption in the first period of life which produce a positive impact on the environment. As habits increase, an individual attaches more importance to consumption growth (as opposed to the consumption level) in its utility function. Hence we expect individuals to shift consumption from the present to the future so as to lift up the rate of consumption growth (from which more utility is derived, the higher the habits) which is beneficial to the environment. On the other hand, higher habit yields to an increase of savings. In fact, since habit reduces the marginal rate of intertemporal substitution, it is rational to reduce consumption early in life and increase savings which lead to capital accumulation thus an increase of consumption possibilities in the second period of life which generates a negative impact on the environment. Our characterization of the steady state shows that, as regards the environment, the positive impact overcomes the negative one. This result is straightforward and clearer, which eliminates the ambiguousness of the one achieved by Ono (2002) who provided a certain condition 


\section{Articles}

for analyzing environmental consequence of habit formation.

We previously signaled that $\mathrm{SH}$ are always consistent with all proprieties, then higher habits formation lowers the marginal rate of intertemporal substitution becoming rational to reduce consumption early in life, which produce a positive impact on the environment. As habits increase, an individual attaches more importance to consumption growth in its utility function. Hence we expect individuals to shift consumption from the first to the second period so as to lift up the rate of consumption growth which is beneficial to the environment. This result confirms the role of the habits as generally intended in the literature. Wendner (2003b) argues that, at any given consumption point, the indifference curve relating current to future consumption becomes flatter, or, equivalently, the marginal rate of substitution of current consumption for future consumption becomes lower. Thus, an increase in $\sigma$ lowers the MRS, and households react with an increase in their optimal consumption growth factor $c_{t+1}^{2} / c_{t}^{1}$. On the other hand, higher habit yields an increase of saving decisions which lead to capital accumulation, thus an increase in consumption possibilities of old generation through higher production activities which generates a negative impact on the environment. Our characterization of the steady state shows that, as regards the environment, the positive impact overcomes the negative one.

\subsection{Multiplicative habits}

In this subsection, we aim to examine the comparative static analysis at the stable steady state equilibrium of internal habits in their multiplicative form through studying the $\mathrm{MH}$ effects on capital and the environment.

\subsubsection{Laissez-faire Equilibrium}

Households choose $\left\{c_{t}^{1}, c_{t+1}^{2}, s_{t}, m_{t}\right\}$ to maximize his utility (4) according to the following program subject to the life-cycle budget constraint (3) and the environmental equation (6).

Verification of property (1) for multiplicative specification:

$\partial U\left(c_{t+1}^{2}, c_{t}^{1}\right) / \partial c_{t+1}^{2}=\left(c_{t}^{1}\right)^{-\sigma} U^{\prime}\left(\hat{c}_{t+1}^{2}\right)>0$ $\partial U\left(c_{t+1}^{2}, c_{t}^{1}\right) / \partial c_{t+1}^{2}=\frac{1}{c_{t+1}^{2}}>0$

Verification of property (2) for multiplicative specification:

$\partial U\left(c_{t+1}^{2}, c_{t}^{1}\right) / \partial c_{t}^{1}=$

$$
=-\sigma\left(c_{t}^{1}\right)^{-\sigma-1} c_{t+1}^{2} U^{\prime}\left(\hat{c}_{t+1}^{2}\right)<0
$$

$\partial U\left(c_{t+1}^{2}, c_{t}^{1}\right) / \partial c_{t}^{1}=-\sigma \frac{1}{c_{t}^{1}}<0$

Thus, properties (1) and (2) hold for $\mathrm{MH}$.

Verification of property (3) for multiplicative specification:

$\partial U\left(c_{t+1}^{2}, c_{t}^{1}\right) / \partial \sigma=$

$$
=-c_{t+1}^{2}\left(c_{t}^{1}\right)^{-\sigma} \ln c_{t}^{1} U^{\prime}\left(\hat{c}_{t+1}^{2}\right)
$$

$\partial U\left(c_{t+1}^{2}, c_{t}^{1}\right) / \partial \sigma=-\ln c_{t}^{1}$

This derivative can be positive or negative. It is negative only if $c_{t}^{1}$ is larger than one. If $c_{t}^{1}$ is smaller than or equal to one, the multiplicative form is inconsistent with property (P3). In this case, an increase in the importance of habits raises effective consumption and thereby utility.

Verification of property (4) for multiplicative specification:

The marginal rate of substitution is given by:

$M R S_{c_{t}^{1} / c_{t+1}^{2}}=$ $=\frac{U^{\prime}\left(c_{t}^{1}\right)-\sigma\left(c_{t}^{1}\right)^{-\sigma-1} c_{t+1}^{2} U^{\prime}\left(\hat{c}_{t+1}^{2}\right)-\beta U^{\prime}\left(E_{t+1}\right)}{\left(c_{t}^{1}\right)^{-\sigma} U^{\prime}\left(\hat{c}_{t+1}^{2}\right)}$

Differentiating the marginal rate of substitution with respect to $\sigma$ yields $\frac{\partial M R S_{c_{t}^{1} / c_{t+1}^{2}}}{\partial \sigma}=$ $=\frac{-c_{t+1}^{2} U^{\prime}\left(\hat{c}_{t+1}^{2}\right)+\left(c_{t}^{1}\right)^{1+\sigma} \ln c_{t}^{1} U(1-\rho)\left[1-\beta U^{\prime}\left(E_{t+1}\right)\right]}{c_{t}^{1} U^{\prime}\left(\hat{c}_{t+1}^{2}\right)}$

where 


\section{Articles}

$\rho\left(\hat{c}_{t+1}^{2}\right)=-\hat{c}_{t+1}^{2} U^{\prime \prime}\left(\hat{c}_{t+1}^{2}\right) / U^{\prime}\left(\hat{c}_{t+1}^{2}\right)>0$

Variable $\rho\left(\hat{c}_{t+1}^{2}\right)$ denotes the elasticity of marginal utility with respect to $\hat{c}_{t+1}^{2}$.

Since the utility function is log-linear, $\rho\left(\hat{c}_{t+1}^{2}\right)=1$. Thus,

$$
\frac{\partial M R S_{c_{t}^{1} / c_{t+1}^{2}}}{\partial \sigma}=\frac{-c_{t+1}^{2}}{c_{t}^{1}}<0
$$

Thereby, property (P4) always holds for $\mathrm{MH}$.

We use the constraints (3) and (6) to write down the objective function of the individual as $^{4}$

$\ln c_{t}^{1}+\ln \left[r_{t+1}\left(w_{t}-c_{t}^{1}-m_{t}\right)\left(c_{t}^{1}\right)^{-\sigma}\right]+$

$\ln E_{t}+\ln \left[E_{t}-\beta\left(c_{t}^{1}+c_{t}^{2}\right)+\delta m_{t}\right]$

By deriving (26) with respect to $m_{t}$, we get $R_{t+1} \frac{1}{c_{t+1}^{2}}=\delta \frac{1}{E_{t+1}}$

By deriving (26) with respect to $c_{t}^{1}$, we obtain

$(1+\sigma) \frac{1}{c_{t}^{1}}=(\beta+\delta) \frac{1}{E_{t+1}}$

Equation (28) implies that, in the case of $m>0$, the individual chooses consumption when young, equating the marginal rate of substitution between consumption in youth and environmental quality in old age to the marginal rate of transformation $(\beta+\delta) /(1+\sigma)$. At the utility maximum, a decrease in utility due to falling consumption during youth is equal to an increase in utility due to the sum of an increase in maintenance effort $\delta /(1+\sigma)$, and a decrease in a consumption externality $\beta$.

Equivalently, (27) gives us a simple arbitrage between the rate of return on the private savings, $R_{t}$ and the rate of return on the investment in environmental quality, $\delta$. This condition states that, in the case of $m>0$, the individual chooses savings
Subtractive versus Multiplicative Habits in Environmental Economics

to equate the marginal rate of substitution between the effective consumption in old age and environmental quality in old age to the marginal rate of transformation $\delta / R_{t+1}$. Assuming perfect competition in the factor markets in the $\mathrm{MH}$ as well, the profitmaximization problem yields the first order conditions (11) and (12).

A competitive equilibrium for the economy under analysis is a sequence $\left\{c_{t}^{1^{*}}, c_{t+1}^{2^{*}}, m_{t}^{*}, w_{t}^{*}, R_{t}^{*}, s_{t}^{*}, k_{t}^{*}, E_{t}^{*}\right\}_{t=0}^{\infty} \quad$ such that, given the initial conditions of the state variables $k_{0}$ and $E_{0}$ : i) firms maximize profits; ii) consumers maximize their utility function; iii) markets clear.

The knowledge of the equilibrium paths for the capital level $k$ and the environmental quality $E$ gives all the equilibrium sequences of our model. Hence, we can determinate the dynamics of the capital accumulation and of the environmental quality.

By plugging conditions (11) and (12) into equation (6), the stock of capital in period $t+1$ evolves according to

$k_{t+1}=s_{t}\left(f\left(k_{t}\right)-\right.$

$\left.k_{t} f^{\prime}\left(k_{t}\right), f^{\prime}\left(k_{t+1}\right), E_{t}\right)$

which is a non-linear first-order difference equation that defines implicitly $k_{t+1}$ as a function of $k_{t}$ and $E_{t}$.

Equivalently, the evolution of the environmental quality can be found

$$
\begin{aligned}
& E_{t+1}=E_{t}-\beta\left\{f\left(k_{t}\right)-k_{t} f^{\prime}\left(k_{t}\right)-\right. \\
& \left.\quad S(.)+f^{\prime}\left(k_{t}\right) k_{t}\right\}+\cdots \\
& \quad+\delta m\left\{f\left(k_{t}\right)-k_{t} f^{\prime}\left(k_{t}\right), f^{\prime}\left(k_{t+1}\right), E_{t}\right\}
\end{aligned}
$$

Equations (29) and (30) outline a system of non-linear first order difference equations that sketches the dynamics of the capital accumulation and the evolution of the environmental quality along the competitive equilibrium path of the model. The solution of

\footnotetext{
${ }^{4}$ As with the SH specification, we suppose that the individual's utility function is a log-linear function.
} 


\section{Articles}

this system defines the competitive equilibrium path for capital and environmental quality $\left\{k_{t}^{*}, E_{t}^{*}\right\}_{t=0}^{\infty}$. Once these paths are determined, we can obtain $\left\{c_{t}^{1^{*}} c_{t+1}^{2^{*}}, w_{t}^{*}, R_{t}^{*}, s_{t}^{*}\right\}$ by using (1) and (12).

The law of capital accumulation (29) can be written as

$$
\begin{gathered}
k_{t+1}-s_{t}\left(f\left(k_{t}\right)-k_{t} f^{\prime}\left(k_{t}\right), f^{\prime}\left(k_{t+1}\right), E_{t}\right) \equiv \\
\equiv \Psi\left(E_{t}, k_{t}, k_{t+1}\right)=0
\end{gathered}
$$

In a similar way, we define the evolution of the environmental quality as

$E_{t+1} \equiv \Omega\left(E_{t}, k_{t}, k_{t+1}\right)$

Under the hypothesis that $m>0$ and from the first order conditions of the individual's maximization problem, equation (28) can be rewritten as

$E_{t+1}=\left(\frac{\beta+\delta}{1+\sigma}\right) c_{t}^{1}$

and equation (27) can be solved for $c_{t+1}^{2}$.

$c_{t+1}^{2}=\frac{R_{t+1} E_{t+1}}{\delta}$

Equations (33) and (34) indicate that there exists a fixed proportion between the consumption level of agent and the index of environmental quality.

By taking into consideration the savings market clearing condition (5), we can characterize a relation between $k_{t+1}$ and $E_{t+1}$.

$k_{t+1}=\frac{E_{t+1}}{\delta}$

Now, by getting rid of $m_{t}$ from the budget constraint (1)and plugging it along with (33) and (35) (lagged one period) into the environmental law of motion (6), we get

$$
\begin{gathered}
m_{t}=\left[f\left(k_{t}\right)-k_{t} f^{\prime}\left(k_{t}\right)\right]- \\
-\frac{E_{t+1}}{\delta}-\frac{1+\sigma}{\beta+\delta} E_{t+1}
\end{gathered}
$$

$E_{t+1}=E_{t}-\beta\left[\frac{1+\sigma}{(\beta+\delta)} E_{t+1}+\frac{{ }^{\prime} R_{t}}{\delta} E_{t}\right]$
$+\delta\left[f\left(k_{t}\right)-k_{t} f^{\prime}\left(k_{t}\right)-\frac{E_{t+1}}{\delta}-\frac{1+\sigma}{(\beta+\delta)} E_{t+1}\right]$

By rearranging (37) we get

$$
\begin{aligned}
& E_{t+1}\left[1+\frac{\beta(1+\sigma)}{\beta+\delta}+1+\frac{\delta(1+\sigma)}{\beta+\delta}\right]= \\
& \quad=E_{t}-\beta k_{t} f^{\prime}\left(k_{t}\right)+\delta\left[f\left(k_{t}\right)-k_{t} f^{\prime}\left(k_{t}\right)\right]
\end{aligned}
$$

We define the capital's share of output as $\alpha\left(k_{t}\right)=\frac{k_{t} f^{\prime}\left(k_{t}\right)}{f\left(k_{t}\right)}$. For simplification, we suppose that the parameter $\alpha$ is constant. Under this assumption, (38) reduces to

$E_{t+1}(3+\sigma)=E_{t}-\beta \alpha \mathrm{f}\left(k_{t}\right)+\delta\left[f\left(k_{t}\right)-\alpha f\left(k_{t}\right)\right]$

Consequently, the dynamic equilibrium is provided by the following first-order nonlinear difference equation

$E_{t+1}=\frac{1}{(3+\sigma)}\left\{E_{t}+[\delta(1-\alpha)-\beta \alpha] f\left(k_{t}\right)\right\}$

Some general forms of production function satisfy this assumption; for our analysis we use a Cobb-Douglas function ${ }^{5}$. By plugging $f(k)=k^{\alpha}$ into (40) and using the relationship found in equation (35), we get

$E_{t+1}=\frac{1}{(3+\sigma)}\left\{E_{t}+[\delta(1-\alpha)-\beta \alpha]\left(\frac{E_{t}}{\delta}\right)^{\alpha}\right\}$

Thus, (41) can be written as

$E_{t+1}=g_{0} E_{t}+g_{1}\left(E_{t}\right)^{\alpha}$

where the two constant coefficients are defined as

and

$$
g_{0}=\frac{1}{(3+\sigma)}
$$

$$
g_{1}=\frac{[\delta(1-\alpha)-\beta \alpha]}{\delta^{\alpha}(3+\sigma)}
$$

\footnotetext{
${ }^{5}$ Theoretical and applied researches use extensively the Cobb-Douglas production function.
} 


\section{Articles}

Given the relation between environment and capital shown in (35), we can obtain from (42)a dynamic equation for the evolution of $k$.

$\delta k_{t+1}=g_{0}\left(\delta k_{t}\right)+g_{1}\left(\delta k_{t}\right)^{\alpha}$

By rearranging, we obtain

$$
k_{t+1}=d_{0} k_{t}+d_{1}\left(k_{t}\right)^{\alpha}
$$

where

and

$$
d_{0}=g_{0}=\frac{(1-d)}{(3+\sigma)}
$$

$$
d_{1}=\frac{g_{1}}{\delta^{1-\alpha}}=\frac{[\delta(1-\alpha)-\beta \alpha]}{\delta(3+\sigma)}
$$

The term $g_{0}$ is always larger or equal to zero, whereas the term $g_{1}$ is of ambiguous sign; besides, it can be verified that $g_{0}<1$ (as the denominator is always larger than the numerator). These properties open up the possibility of a rich dynamic behavior. Particularly, the existence of a non-trivial steady state crucially depends on the sign of the terms $g_{1}$ and $d_{1}$. A necessary condition for $g_{1}$ and $d_{1}$ to be positive is: $\delta>\beta[\alpha(1-\alpha)]$. Thus, either better maintenance technologies (higher $\delta$ ) or lower environmental deterioration by consumption (lower $\beta$ ) is required. Conversely, neither agent's habit stock seems to affect the existence of the steady state.

\subsubsection{The stability properties of the long-run equilibrium}

It is also useful to examine the stability properties of the long-run equilibrium. Firstly, we figure out the steady states of our two dimensional differential system. It is easy to show that there are two steady states. The first one is trivial, that is

$$
\left(\overline{E_{0}}, \bar{k}_{0}\right)=(0,0)
$$

The second one is found after some computation. We start by solving (42)

From this, we get
Subtractive versus Multiplicative Habits in Environmental Economics

$$
\overline{E_{1}}=\left(\frac{g_{1}}{\left(1-g_{0}\right)}\right)^{\frac{1}{1-\alpha}}
$$

Similarly, equation (44) reduces to

$$
\bar{k}=d_{0} \bar{k}+d_{1} \bar{k}^{\alpha}
$$

and it is solved by

$\overline{k_{1}}=\left(\frac{d_{1}}{\left(1-d_{0}\right)}\right)^{\frac{1}{1-\alpha}}$

Thus, the non trivial steady state is as follows

$$
\left(\overline{E_{1}}, \overline{k_{1}}\right)=\left(\left(\frac{g_{1}}{\left(1-g_{0}\right)}\right)^{\frac{1}{1-\alpha}},\left(\frac{d_{1}}{\left(1-d_{0}\right)}\right)^{\frac{1}{1-\alpha}}\right)
$$

The Hartman-Grobman theorem states the topological equivalence between linear and nonlinear systems. By bearing in mind this topological equivalence, the stability of the fixed point of the nonlinear system can be determined by examining the eigenvalues of the Jacobian matrix. We can deduce that, under the hypotheses we made on the functional form of the utility and production function and the size of the parameter $\delta$ and $\beta$, the system converges to a long-run equilibrium which is asymptotically stable.

Proof. See Appendix C.

\subsubsection{The steady state}

We define now the comparative static behaviour of the steady state we have determined under the particular assumptions made on the utility and production functions.

Let us write (42) as

$$
\bar{E}=\left(\frac{\frac{[\delta(1-\alpha)-\beta \alpha]}{\delta^{\alpha}(3+\sigma)}}{1-\frac{1}{3+\sigma}}\right)^{\frac{1}{1-\alpha}}
$$

After some rearrangements (49) simplifies to

$$
\bar{E}=\left(\frac{[\delta(1-\alpha)-\beta \alpha]}{\delta^{\alpha}(2+\sigma)}\right)^{\frac{1}{1-\alpha}}=\Omega^{\frac{1}{1-\alpha}}
$$




\section{Articles}

where $\Omega=\frac{[\delta(1-\alpha)-\beta \alpha]}{\delta^{\alpha}(2+\sigma)}$

Similarly, we rewrite (44) as

$\bar{k}=\left(\frac{\frac{[\delta(1-\alpha)-\beta \alpha]}{\delta(3+\sigma)}}{1-\frac{1}{3+\sigma}}\right)^{\frac{1}{1-\alpha}}$

By simplifying and rearranging the above equation, we obtain

$\bar{k}=\left(\frac{[\delta(1-\alpha)-\beta \alpha]}{\delta(2+\sigma)}\right)^{\frac{1}{1-\alpha}}=\Psi^{\frac{1}{1-\alpha}}$

where $\Psi=\frac{[\delta(1-\alpha)-\beta \alpha]}{\delta(2+\sigma)}$

\subsubsection{The effects of multiplicative habits}

\section{on capital and environment}

Now we study the effects of habit formation in multiplicative form on the steady state equilibrium level of capital accumulation and environmental quality.

From the system of equations (50) and (52) characterizing the steady state, we have

$\frac{\partial \bar{E}}{\partial \sigma}=\frac{1}{1-\alpha} \Omega^{\frac{\alpha}{1-\alpha}}\left(\frac{-\delta^{\alpha}[\delta(1-\alpha)-\beta \alpha]}{\delta^{2 \alpha}(2+\sigma)^{2}}\right)<0$

$\frac{\partial \bar{k}}{\partial \sigma}=\frac{1}{1-\alpha} \Psi^{\frac{\alpha}{1-\alpha}}\left(\frac{-\delta[\delta(1-\alpha)-\beta \alpha]}{\delta^{2}(2+\sigma)^{2}}\right)<0$

Proposition: with multiplicative specification, economies with higher habit stock have less capital accumulation and a worse environmental quality in steady state.

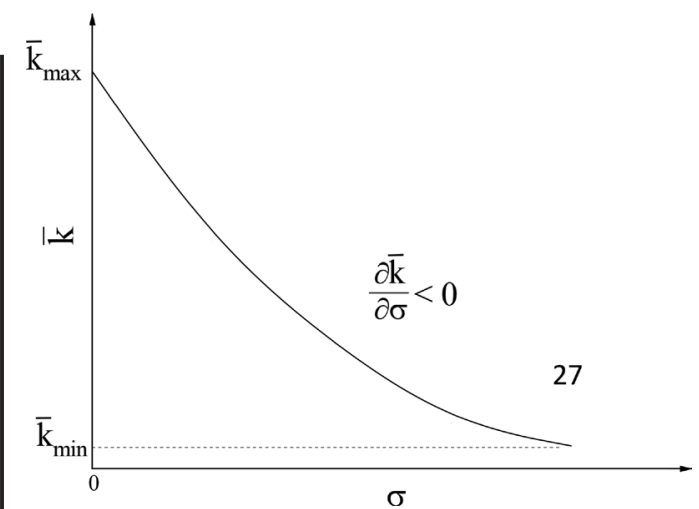

Fig. 3: Effect of $\mathrm{MH}$ on environmental quality

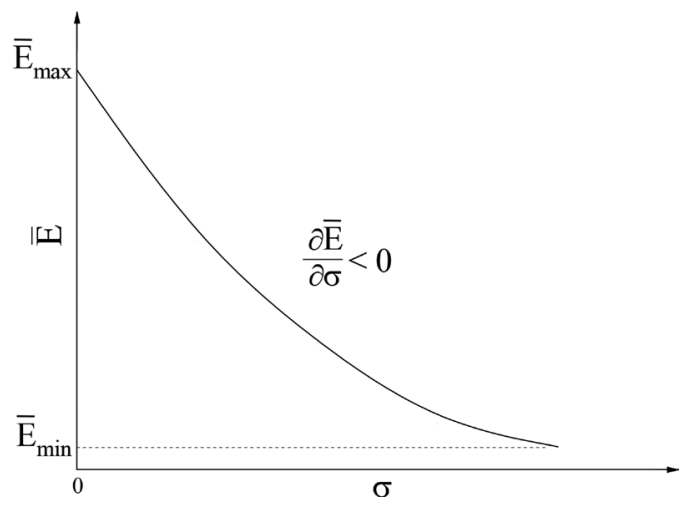

Fig. 4: Effect of $\mathrm{MH}$ on capital accumulation

Our analysis of MH's impact on capital accumulation and environmental quality reveals that $\mathrm{MH}$ formation affects negatively the capital and the environment as opposed to our finding with $\mathrm{SH}$. Bossi and Porqueras (2009) and Wendner (2003) have had the same finding in non-environmental framework.

In fact: $\mathrm{MH}$ is not always consistent with the properties that assure the role of habits. Thereby, the mechanism in which direction (higher $\mathrm{E}$ or lower $\mathrm{E}$ ) the effects of $\mathrm{MH}$ work may be the opposite of the one with $\mathrm{SH}$. Consequently, a higher $\mathrm{MH}$ increases the marginal rate of intertemporal substitution becoming rational to increase consumption early in life which affects the environment negatively. This increase in first period consumption reduces savings which on one 


\section{Articles}

hand lowers the capital accumulation and on the other hand reduces consumption when old which affects the environment positively. The characterization of the steady state shows that the negative impact of increasing consumption in youth overcomes the positive one of reducing consumption when old, which leads to worsening the environment. Therefore, in response to a rise in $\sigma$, the representative household lowers its optimal consumption growth rate which is inconsistent with the very idea of habit persistence existing in the literature and thus introducing the habits may reduce the desire to smooth consumption.

\section{Conclusion}

Standard

neoclassical-economic

framework keeps focus on policy that highlights the effect of income and prices on behavior. But, it does not define a truthful and an entire picture of household behavior. Limited rationality and aspects, other than income and prices, such as internal habit formation in consumption shape consumer preferences. We tackled this issue in environmental economics.

We develop an overlapping generations model with internal habits in consumption and the presence of environmental quality in the utility function using two different specifications of habits. We focus particularly on exploring and comparing the impact of increasing the weight of first subtractive and second multiplicative habit on environmental quality and capital accumulation by studying the comparative static analysis at the stable steady state equilibrium.

The modeling of habits implies that consumer preferences are influenced not only by a household's own current consumption, but also by its personal past. In the literature, internal habit formation has often been introduced to raise the agents' desire to smooth consumption over time. However, by
Subtractive versus Multiplicative Habits in Environmental

Economics

changing the way the habit is specified, we find that this consensus does not always hold. We have shown that introducing habit in its subtractive specification can lead to different findings compared to those with multiplicative specification. The different forms of internal habits may affect the consumer willingness to substitute present for future consumption and therefore the steady state equilibrium of the economy. Thus, one may be expecting an (eventually) converse effect on environmental quality and capital accumulation.

\section{Appendices}

\section{Appendix A}

In our case, we should be able to prove that

$\left\{\begin{array}{l}\left|\frac{\mu_{1}+\mu_{4}+\sqrt{\left(\mu_{1}-\mu_{4}\right)^{2}+4 \mu_{2} \mu_{3}}}{2}\right|<1 \\ \left|\frac{\mu_{1}+\mu_{4}-\sqrt{\left(\mu_{1}-\mu_{4}\right)^{2}+4 \mu_{2} \mu_{3}}}{2}\right|<1\end{array}\right.$

and this is true if

$\mu_{1}+\mu_{4}<0$

Hence we can conclude that the system converges to a long-run equilibrium which is asymptotically stable if $\mu_{1}<-\mu_{4}$.

Furthermore,

$\left\{\begin{array}{l}\mu_{1}+\mu_{4}+\sqrt{\left(\mu_{1}-\mu_{4}\right)^{2}+4 \mu_{2} \mu_{3}}>0 \\ \mu_{1}+\mu_{4}-\sqrt{\left(\mu_{1}-\mu_{4}\right)^{2}+4 \mu_{2} \mu_{3}}<0\end{array}\right.$

Therefore, we get

$\left\{\begin{array}{c}\sqrt{\left(\mu_{1}-\mu_{4}\right)^{2}+4 \mu_{2} \mu_{3}}>-\left(\mu_{1}+\mu_{4}\right) \\ \sqrt{\left(\mu_{1}-\mu_{4}\right)^{2}+4 \mu_{2} \mu_{3}}>\mu_{1}+\mu_{4}\end{array}\right.$

Thus, we obtain

$-\mu_{1} \mu_{4}+\mu_{2} \mu_{3}>0$

This let us conclude that the determinant of the left-hand-side matrix $|\Delta|=\mu_{1} \mu_{4}-\mu_{2} \mu_{3}$ is negative. 


\section{Articles}

\section{Appendix B:}

The conditions of the equilibrium characterize two equations system with two unknowns. That's why the rank of this system must be equal to 2 . Thus, the determinant $\Delta$ must be different from 0 . The equilibrium condition system is then a Cramer system.

The system's resolution by Cramer's rule:

We have $J=\left[\begin{array}{ll}\mu_{1} & \mu_{2} \\ \mu_{3} & \mu_{4}\end{array}\right]$ and $\mathrm{P}=\left[\begin{array}{l}\mu_{5} \partial \sigma \\ \mu_{6} \partial \sigma\end{array}\right]$ This gives $J_{1}=\left[\begin{array}{ll}\mu_{5} \partial \sigma & \mu_{2} \\ \mu_{6} \partial \sigma & \mu_{4}\end{array}\right]$ and $J_{2}=\left[\begin{array}{ll}\mu_{1} & \mu_{5} \partial \sigma \\ \mu_{3} & \mu_{6} \partial \sigma\end{array}\right]$

$\partial \bar{k}=\frac{\left|J_{2}\right|}{|\Delta|}=\frac{\left|\mu_{1} \mu_{6} \partial \sigma-\mu_{3} \mu_{5} \partial \sigma\right|}{|\Delta|}$ $\Rightarrow \frac{\partial \bar{k}}{\partial \sigma}=\frac{1}{|\Delta|}\left\{\mu_{1} \mu_{6}-\mu_{3} \mu_{5}\right\}>0$

$$
\begin{aligned}
& \partial \bar{E}=\frac{\left|J_{1}\right|}{|\Delta|}=\frac{\left|\mu_{4} \mu_{5} \partial \sigma-\mu_{2} \mu_{6} \partial \sigma\right|}{|\Delta|} \\
& \Rightarrow \frac{\partial \bar{E}}{\partial \sigma}=\frac{1}{|\Delta|}\left\{\mu_{4} \mu_{5}-\mu_{2} \mu_{6}\right\}>0
\end{aligned}
$$

Determination of $\mu_{4} \mu_{5}-\mu_{2} \mu_{6}$ sign:

$\mu_{4} \mu_{5}-\mu_{2} \mu_{6}=$ $=\frac{(\beta+\delta)^{2} \delta f^{\prime} \bar{E}}{\left[(\beta+\delta) f^{\prime}+\delta \sigma\right]^{2}}\left[f^{\prime \prime} \bar{E}-\delta\left(f^{\prime}+\bar{k} f^{\prime \prime}+\delta \sigma\right)\right]$ $-\delta(\delta \bar{k}-2 \bar{E})\left[\frac{(\beta+\delta) \sigma \delta f^{\prime \prime} \bar{E}}{\left[(\beta+\delta) f^{\prime}+\delta \sigma\right]^{2}}+\right.$ $\left.+\beta f^{\prime}+(\beta+\delta) \bar{k} f^{\prime \prime}+\delta\right]$

Rearranging equation (23) gives

$$
\bar{k}=\frac{\left[(\beta+\delta) f^{\prime}+2 \delta \sigma\right] \bar{E}}{\delta\left[(\beta+\delta) f^{\prime}+\delta \sigma\right]}
$$

Thus,

$$
\begin{gathered}
\mu_{4} \mu_{5}-\mu_{2} \mu_{6}=\frac{\delta \bar{E}}{\left[(\beta+\delta) f^{\prime}+\delta \sigma\right]^{2}}\left\{(\beta+\delta)^{2} f^{\prime} f^{\prime \prime} \bar{E}-(\beta+\delta)^{2} \delta f^{\prime}\left(f^{\prime}+\bar{k} f^{\prime \prime}+\delta \sigma\right)\right. \\
-\frac{(\beta+\delta) \delta \sigma\left[(\beta+\delta) f^{\prime}+2 \delta \sigma\right] f^{\prime \prime} \bar{E}}{\left[(\beta+\delta) f^{\prime}+\delta \sigma\right]}+2(\beta+\delta) \delta \sigma f^{\prime \prime} \bar{E} \\
-\left[(\beta+\delta) f^{\prime}+2 \delta \sigma\right]\left[(\beta+\delta) f^{\prime}+\delta \sigma\right]\left[\beta f^{\prime}+(\beta+\delta) \bar{k} f^{\prime \prime}+\delta\right] \\
\left.+2\left[(\beta+\delta) f^{\prime}+\delta \sigma\right]^{2}\left[\beta f^{\prime}+(\beta+\delta) \bar{k} f^{\prime \prime}+\delta\right]\right\} \\
\{\ldots\}=\frac{(\beta+\delta)^{2} f^{\prime} f^{\prime \prime} \bar{E}\left[(\beta+\delta) f^{\prime}+2 \delta \sigma\right]}{\left[(\beta+\delta) f^{\prime}+\delta \sigma\right]}-(\beta+\delta)^{2} \delta f^{\prime}\left(f^{\prime}+\bar{k} f^{\prime \prime}+\delta \sigma\right) \\
+(\beta+\delta) f^{\prime}\left[(\beta+\delta) f^{\prime}+\delta \sigma\right]\left[\beta f^{\prime}+(\beta+\delta) \bar{k} f^{\prime \prime}+\delta\right]
\end{gathered}
$$

Plugging equation (23) yields

$\{\ldots\}=(\beta+\delta) f^{\prime}\left\{-\delta(\beta+\delta) f^{\prime}-\delta^{2} \sigma(\beta+\delta)\right.$

$\left.+\left[(\beta+\delta) f^{\prime}+\delta \sigma\right]\left[\beta f^{\prime}+(\beta+\delta) \bar{k} f^{\prime \prime}+\delta\right]\right\}$

Therefore,

$\mu_{4} \mu_{5}-\mu_{2} \mu_{6}=\frac{\delta \bar{E}(\beta+\delta) f^{\prime}}{\left[(\beta+\delta) f^{\prime}+\delta \sigma\right]^{2}}\left\{-\delta(\beta+\delta)\left(f^{\prime}+\delta \sigma\right)\right.$
$\left.+\left[(\beta+\delta) f^{\prime}+\delta \sigma\right]\left[\beta f^{\prime}+(\beta+\delta) \bar{k} f^{\prime \prime}+\delta\right]\right\}$ which implies that the sign of $\mu_{4} \mu_{5}-\mu_{2} \mu_{6}$ depends on the sign of the following expression:

$\left[(\beta+\delta) f^{\prime}+\delta \sigma\right]\left[\beta f^{\prime}+(\beta+\delta) \bar{k} f^{\prime \prime}+\delta\right]-$

$-\delta(\beta+\delta)\left(f^{\prime}+\delta \sigma\right)$

$\leftrightarrow \frac{\left[(\beta+\delta) f^{\prime}+\delta \sigma\right]}{\delta(\beta+\delta)\left(f^{\prime}+\delta \sigma\right)} \lesseqgtr \frac{1}{\left[\beta f^{\prime}+(\beta+\delta) \bar{k} f^{\prime \prime}+\delta\right]}$ 


\section{Articles}

Given our hypothesis,

$$
\begin{aligned}
& {\left[\beta f^{\prime}+(\beta+\delta) \bar{k} f^{\prime \prime}+\delta\right]>0,} \\
& \underbrace{\frac{\left[(\beta+\delta) f^{\prime}+\delta \sigma\right]}{\delta\left[(\beta+\delta) f^{\prime}+(\beta+\delta) f^{\prime} \delta \sigma\right]}}_{<1} \lesseqgtr \\
& \lesseqgtr \underbrace{\frac{1}{\left[\beta f^{\prime}+(\beta+\delta) \bar{k} f^{\prime \prime}+\delta\right]}}_{>1}
\end{aligned}
$$

So,

$$
\begin{aligned}
& \frac{\left[(\beta+\delta) f^{\prime}+\delta \sigma\right]}{\delta\left[(\beta+\delta) f^{\prime}+(\beta+\delta) f^{\prime} \delta \sigma\right]}< \\
& <\frac{1}{\left[\beta f^{\prime}+(\beta+\delta) \bar{k} f^{\prime \prime}+\delta\right]}
\end{aligned}
$$

Thus,

$$
\begin{array}{r}
{\left[(\beta+\delta) f^{\prime}+\delta \sigma\right]\left[\beta f^{\prime}+(\beta+\delta) \bar{k} f^{\prime \prime}+\delta\right]-} \\
-\delta(\beta+\delta)\left(f^{\prime}+\delta \sigma\right)<0
\end{array}
$$

\section{Appendix C:}

We first set up the Jacobian matrix of partial derivatives.

$$
\begin{gathered}
J_{(E, k)}=\left[\begin{array}{cc}
\frac{\partial E_{t+1}}{\partial E_{t}} & \frac{\partial E_{t+1}}{\partial k_{t}} \\
\frac{\partial k_{t+1}}{\partial E_{t}} & \frac{\partial k_{t+1}}{\partial k_{t}}
\end{array}\right] ; \\
J=\left[\begin{array}{cc}
g_{0}+\alpha g_{1} E^{\alpha-1} & 0 \\
0 & d_{0}+\alpha d_{1} k^{\alpha-1}
\end{array}\right]
\end{gathered}
$$

Second, we evaluate the Jacobian $J$ at the steady state.

$J_{\left(\overline{E_{1}}, \bar{k}_{1}\right)}=A=\left[\begin{array}{cc}g_{0}+\alpha g_{1}\left(\frac{\left(1-g_{0}\right)}{g_{1}}\right) & 0 \\ 0 & d_{0}+\alpha d_{1}\left(\frac{\left(1-d_{0}\right)}{d_{1}}\right)\end{array}\right]$

The eigenvalues are obtained by solving the characteristic polynomial $p(\lambda)=\operatorname{det}(A-\lambda I)=0$.

$p(\lambda)=\left|\begin{array}{cc}g_{0}+\alpha\left(1-g_{0}\right)-\lambda & 0 \\ 0 & d_{0}+\alpha\left(1-d_{0}\right)-\lambda\end{array}\right|=0$
Subtractive versus Multiplicative Habits in Environmental Economics

The matrix $A$ is diagonal, hence its eigenvalues $\lambda_{i}$ are its diagonal elements. We have one real eigenvalue with multiplicity two, since $d_{0}=g_{0}$.

$$
\lambda_{1,2}=g_{0}(1-\alpha)+\alpha
$$

Following Azariadis (1993), a steady state $(\bar{E}, \bar{k})$ is a sink (or asymptotically stable) if all the eigenvalues of the Jacobian matrix of partial derivatives have module strictly less than one, that is $\left|\lambda_{i}\right|<1$ for all $i$.

In our case, we should be able to prove that

$\left|g_{0}(1-\alpha)+\alpha\right|<1$

and it is easily shown that this is true. Actually we have already shown that $g_{0}$ is always positive, hence we can write (47) as

$g_{0}(1-\alpha)+\alpha<1$

After some computation (48) reduces to

$$
g_{0}<1
$$

which is always true, as we have mentioned previously.

\section{References}

Abel, A. (1990). Asset prices under habit formation and catching up with the joneses. American Economic Review, 80, 38-42.

Alvarez-Cuadrado, F. (2007). Envy, leisure, and restrictions on working hours. Canadian Journal of Economics, 40, 1286-1310.

Aronsson, T. and Johansson-Stenman, $\mathrm{O}$. (2014). State-variable public goods and social comparisons, Journal of Environmental Economics and Management, 68(2), 390-410. Arrow, K. (1973). Social responsibity and economic efficiency, Public Policy, 21, 303-317. Azariadis, C. (1993). Intertemporal Macroeconomics. Blackwell, Oxford.

Bezin, E. (2013). The dynamics of environmental concern and the evolution of 


\section{Articles}

pollution. Working Paper SMART - LERECO N¹3.09.

Bossi, L., and Gomis-Porqueras, P. (2009). Consequences of modeling habit persistence. Macroeconomic Dynamics, 13(3), 349-365.

Bovemberg, L.A., and Smulders,. S. (1995). Environmental quality and pollution-saving technological change in a two-sector endogenous growth model. Journal of Public Economics, 57, 369-391.

Bunzel, H., (2006). Habit persistence, money, and overlapping generations, Journal of Economic Dynamics and Control, 30, 24252445.

Carroll, C., Overland, J., and Weil, D. (1997). Comparison utility in a growth model. Journal of Economic Growth, 2(4), 339-367.

Carroll, C., Overland, J., and Weil, D. (2000). Saving and growth with habit formation. American Economic Review, 90, 1-15.

Carroll, C., Crawley, E., Slacalek, J., Tokuoka, K., and White, M. N. (2020). Sticky Expectations and Consumption Dynamics. American Economic Journal: Macroeconomics, 12, 40-76.

Chen, H. J., and Li, M. C. (2011). Environmental tax policy, habit formation and nonlinear dynamics. Nonlinear Analysis:Real World Applications, 12, 246-253.

Chetty, R., and Szeidl, A. (2016). Consumption Commitments and Habit Formation. Econometrica, Econometric Society, 84, 855890.

Constantinides, G. (1990). Habit formation: a resolution of the equity premium puzzle. Journal of Political Economy, 98, 519-43.

Deaton, A. S. (1992). Understanding consumption, Oxford University Press, New York.
Havranek, T., Rusnak, M., and Sokolova, A. (2018). Habit formation in consumption: A meta-analysis. European Economic Review, 95, 142-167.

John A., and Pecchenino, R. (1994). An overlapping generations model of growth and the environment. The Economic Journal, 104, 1393-1410.

Klöckner, C. A, Matthies, E., and Hunecke, M. (2003). Problems of operationalizing habits and integrating habits in normative decisionmaking models. Journal of Applied Social Psychology, 33, 396-417.

Klöckner, C. A, and Matthies, E. (2004). How habits interfere with norm-directed behaviour: a normative decisionmaking model for travel mode choice. Journal of Environmental Psychology, 24, 319-327.

Lahiri, A. and Puhakka, M. (1998). Habit persistence in overlapping generations economies under pure exchange. Journal of Economic Theory, 78, 176-186.

Lofgren, A. (2003). Habit formation in the environmental quality: dynamic optimal environmental taxation. Working Papers in Economics no. 92.

Ono, T. (2002). Is habitual consumption harmful to the environment? Economics Bulletin, 17(1), 1-10.

Ono, T. (2003). Environmental tax policy and long-run economic growth. The Japanese Economic Review, 54, 203-217.

Schumacher, I. and Zou, B. (2008). Pollution perception: A challenge for intergenerational equity. Journal of Environmental Economics and Management, 55, 296-309.

Smith, A. (1790). The theory of moral sentiments. Republished in the series Cambridge Texts in the History of Philosophy, edited by KnudHaakonssen, 2002. 
Valente, S. (2006). Notes on habit formation and socially optimal growth. Working paper 06/48, Center of Economic Research, ETH Zürich, Switzerland.

Wendner, R. (2000a). Habit formation and environmental policy: an overlapping generations approach. mimeo.

Wendner, R. (2000b). Environmental externalities and consumer's frames of reference. Stanford Institute for Economic
Policy Research. Discussion. Paper No. 0010.

Wendner, R. (2000c). A policy lesson from an overlapping generations model of habit persistence. Burch Center Working Paper B00-02, University of California, Berkeley: Department of Economics.

Wendner, R. (2003). Do habits raise consumption growth? Resource Economics, 57, 151-163. 